\title{
Diffusion equation modeling for sound energy flow analysis in multi domain structures
}

\author{
Zühre Sü Güla) \\ Department of Architecture, Bilkent University, Ankara, 06800, Turkey \\ Erinç Odabaş \\ MEZZO Stüdyo Ltd, Ankara, 06800, Turkey \\ Ning Xiang \\ Graduate Program in Architectural Acoustics, School of Architecture, Rensselaer Polytechnic Institute, Troy, \\ New York 12180, USA \\ Mehmet Çalışkan
Department of Mechanical Engineering, Middle East Technical University, Ankara, 06800, Turkey
}

(Received 12 August 2018; revised 21 November 2018; accepted 26 November 2018; published online 30 April 2019)

\begin{abstract}
This study investigates reliable models and methods to be applied in sound field analysis of multidomain structures. The case structures are two monuments, namely, Süleymaniye Mosque and Hagia Sophia in İstanbul. These are both multi-volume spaces with many smaller sub-volumes coupled to each other by coupling apertures in form of arches. A key concern of the study is to examine energy flow decays and understand the mechanism of multi-slope sound energy decays. The methodology involves diffusion equation model (DEM) application in a finite-element scheme for sound energy flow analysis. Energy flow decays, energy flow dips, and spatial flow vectors are examined for single versus multi-domain DEM solutions. It is concluded that specification of different domains with individual diffusion coefficients is a critical setting such that, if not assigned correctly, may mislead the results. The energy flow vector analysis has enabled us to comprehend the architectural features in relation to such energy flow decay dip occurrence. The computational efficiency of DEM is also discussed. The DEM application in this study has proved to be a powerful and practical method in room acoustics applications, specifically for multi-rate decay investigations. @ 2019 Acoustical Society of America. https://doi.org/10.1121/1.5095877
\end{abstract}

Pages: $2703-2717$

\section{INTRODUCTION}

Sound energy decay analysis is essential in room acoustics predictions for predicting key characteristics of an enclosure. Alternative modeling and analysis methods are developed initially to estimate acoustical indicators in single volume spaces, where dominantly the energy decay is exponential and has a single linear decay term. Simulation tools that apply geometrical acoustics principles ${ }^{1,2}$ are commonly utilized in the design of different types of venues. Afterwards, the focus has shifted towards developing techniques in estimating and analyzing sounds fields of coupled volume systems where multi-slope sound energy decay occurrence is probable. In this study, the key concern is to discuss reliable models and methods to be applied in sound field analysis of multi-domain structures. This work studies two monumental landmark structures, namely, Süleymaniye Mosque and Hagia Sophia in İstanbul, in that respect.

State of the art non-exponential energy decay investigations in coupled volume spaces address different models that include statistical theory, ${ }^{3,4}$ statistical energy analysis,,${ }^{5-7}$ diffusion equation modeling, ${ }^{8-12}$ wave theory ${ }^{13,14}$ and geometrical acoustics. ${ }^{15-17}$ Non-exponential energy decay can be a

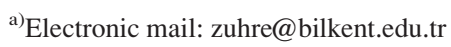

matter of modest-sized two coupled rooms. ${ }^{5}$ The phenomena can also be observed in large-scale structures with multi subvolumes connected to a main space, as of basilicas, ${ }^{7,18}$ cathedrals ${ }^{6,19}$ or mosques. ${ }^{11}$ Selection of the proper model for a specific case and purpose is a critical decision.

A previous study presents the multi-rate energy decay detection in Süleymaniye Mosque and Hagia Sophia. ${ }^{20}$ The collected data in field tests are analyzed for quantifying multi-rate energy decay parameters by Bayesian probabilistic inference, which is an efficient method for estimating key characteristics of multiple slope sound energy decays. ${ }^{21,22}$ The research has further detailed for Süleymaniye Mosque in order to understand the mechanisms of non-exponential decay formation by applying diffusion equation modeling (DEM) in a single domain solution. ${ }^{11,12}$ The effect of multislope decay formation in such mega multi-volume structures can be better discussed through diffusion equation modeling, which is the main methodology of this research. The DEM solution enables us to visualize spatial sound energy distribution with a higher computational efficiency in comparison to ray-tracing simulations. The DEM also provides energy flow decays and spatial flow vectors in the same simulation run.

In this study, the acoustical model of Süleymaniye Mosque is re-constructed for sub-volumes depicting multidomains via different diffusion coefficients in DEM. Results 
are compared to investigations of single volume, single diffusion coefficient DEM solution of the previous model. ${ }^{11}$ Furthermore, both single and multi-domain acoustical models of Hagia Sophia are generated for the DEM to be solved in a finite-element platform. Sound energy flow decays are calculated at field-tested receiver positions. Results highlight that energy flow decay analysis in a multi-domain DEM solution is an effective approach for both detecting multirate decay, and for understanding the major architectural features of multi-volume structures in terms of energy flow feedback mechanisms.

One key parameter within the DEM simulation framework is the diffusion coefficient. This work advances the DEM application on a single domain solution ${ }^{11}$ by applying multi-domain spaces with individual, specific, diffusion coefficients. Both Süleymaniye Mosque and Hagia Sophia have side aisles or galleries connected to a main volume through arches of different sizes. The total volume and sizes of coupling apertures (arches) of case structures are significantly different from one another. Hagia Sophia has almost twice the volume of Süleymaniye Mosque, whereas the arches separating main volume from side aisles are almost one fourth in size as those in Süleymaniye Mosque. For that reason, it is important to apply a reliable factor in their comparison of energy dip formation in single versus multidomain DEM solutions.

This study utilizes the mean coupling factor, as an indicator of the strength of acoustical coupling, in the sound field comparisons of case structures. As previously discussed by Billon et al., ${ }^{8}$ mean coupling factor takes into account the aperture and absorption areas of individual volumes (or domains) coupled to each other. Mean coupling factors indicate that for both case structures, coupling of main domain to sub-domains can be considered as weak. The DEM results are compared for single and multi-domain DEM solutions. It is concluded that when coupling is sufficiently weak, multidomain DEM application is more reliable for assessment of multi-slope decay formation.

This paper is structured as follows. Section II sets out the major architectural features of case structures and field test configurations. Section III specifies applied diffusion equation model equations and numerical implementation. In Sec. IV, the results are discussed. Section V concludes the paper by emphasizing the major findings.

\section{MATERIALS}

\section{A. Case structures}

This section summarizes main architectural features of case structures. Süleymaniye Mosque, which is still one of the landmark monuments in İstanbul, was built during the Ottoman Empire era (1550-1557). The Mosque has a central dome that is supported on two sides by semi domes. Side aisles are sheltered by five smaller domes. The nearly square inner plan of the mosque is $63 \mathrm{~m}$ by $69 \mathrm{~m}$. The main dome has a diameter of $26.20 \mathrm{~m}$. The height of the main dome from the ground to the keystone is $47.75 \mathrm{~m}^{23-25}$ The middle and corner domes on the side aisles have the diameter of $9.90 \mathrm{~m}$, and the others have the diameter of $7.20 \mathrm{~m}$. Its major vertical supports are the four elephant feet underneath main dome, and eight columns carrying secondary arches. The arches between the elephant feet and exterior shell walls support the corner domes. The interior walls of Süleymaniye Mosque are faced with stone revetments out of marble and limestone. The brick dome masonry is painted and then decorated with gold-foiled pen paintings. ${ }^{25}$ The floor finish of the mosque is carpet.

Hagia Sophia was constructed initially as a church in İstanbul in between 532 and 537. After the Ottoman conquest in 1453, it was converted from church to mosque. Upon an initiative from Mustafa Kemal Atatürk in 1932, Hagia Sophia started to function as a museum. As of today, Hagia Sophia is an expanded dome basilica with an interior length of $73.50 \mathrm{~m}$ and a width of $69.50 \mathrm{~m}$, excluding the narthex and the apse. A rectangular plan is sheltered by a central dome between two half domes. The central, slightly elliptical dome has a diameter of $31.25 \mathrm{~m}$ on one axis and $32.80 \mathrm{~m}$ along the other, and rises $55 \mathrm{~m}$ above the pavement of the nave. Columns, smaller arches, and vaults are the loadbearing elements of the side aisles. ${ }^{26,27}$ In Hagia Sophia, there is an additional floor level, where the aisles of the balcony are connected to the main volume with various sized arches. Brick and stone, including limestone, marble, and granite are the major materials applied for the above-ground structure. As of today, the floor pavement is made up of large rectangular marble slabs.

\section{B. Field test configurations}

The outcomes of acoustical field tests have previously been presented for SüleymaniyeMosque ${ }^{11,28}$ and HagiaSophia. ${ }^{20}$ This section compares specific source-receiver configurations in the DEM analysis. The measurement system includes a B\&K (type 4292 -L) standard dodecahedron omni-power sound source, B\&K (type 2734-A) power amplifier, and B\&K (Type 4190ZC0032) microphone covering the frequency interval in between 100 and $8000 \mathrm{~Hz}$. Sampling frequency of the recorded multispectrum impulse is $48 \mathrm{kHz}$. The height of the omni-directional sound source is kept at $1.5 \mathrm{~m}$, and the microphone height is $1.2 \mathrm{~m}$ above the floor. There are three source (S1-S3) and eight receiver positions (R1-R8) in Süleymaniye Mosque (Fig. 1, on the left), whereas three source positions (S1-S3) and six receiver positions (R1-R8) are selected in Hagia Sophia (Fig. 1, on the right). The sound source and receiver positions, all located at ground floor level, are tested in various configurations within given time limits of measurement permission.

\section{METHOD OF ANALYSIS}

The major methodology of this research is DEM application in room acoustics. As discussed in previous literature, ${ }^{29-33}$ the DEM is based on the sound particle concept under the assumption that particles travel along straight lines at the speed of sound in the interior space and multiple diffuse reflections occur at the room boundaries which can be conceived as scattering objects. In DEM, sound radiation is treated in a similar way to electromagnetic radiation, where the propagation of radiation through a medium is mainly affected by absorption and scattering processes. This study 

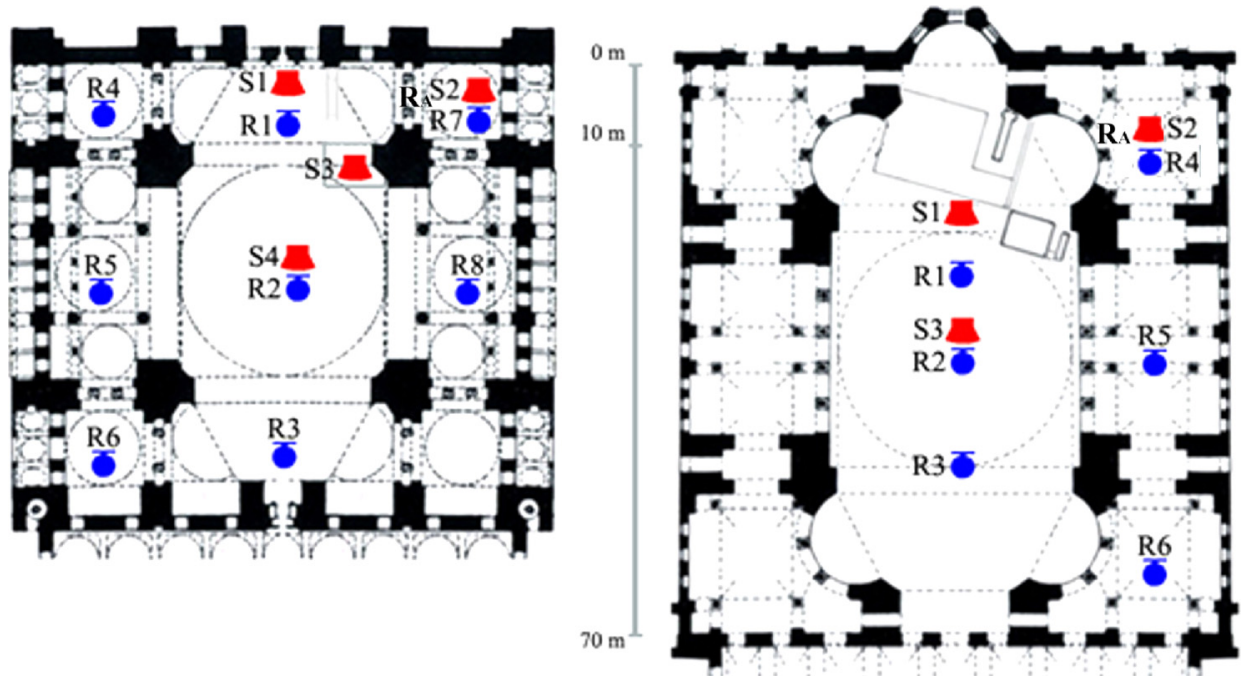

FIG. 1. (Color online) Plan views of Süleymaniye Mosque (on the left) and Hagia Sophia (on the right); Source (S in red) and Receiver ( $\mathrm{R}$ in blue) locations of field tests.

employs the DEM to simulate the reverberation processes in the case structures.

\section{A. Diffusion equation model}

This section presents the governing interior and boundary equations within scope of the DEM that fits most properly to the structures under discussion.

\section{Interior diffusion equation}

When interior surfaces of a single-volume enclosure are diffusely reflecting, the sound energy flow vector $J$ caused by the gradient of the sound energy density $w$ at position $(r)$, and time $(t)$ can be expressed by Fick's law ${ }^{29,32}$

$$
J(r, t)=-D \nabla w(r, t),
$$

where $D$ is the diffusion coefficient, which takes into account the room morphology via $\lambda$ which is mean free path (MFP) ${ }^{33}$ given by

$$
D=\frac{\lambda c}{3}=\frac{4 V c}{3 S},
$$

where $V$ is the volume of the room and $S$ is the total surface area of the room and $c$ is speed of sound. Under the assumption that the sound energy density $w$ in a region (domain $V$ ), excluding sound sources, changes per unit time ${ }^{34}$ as

$$
\partial w(r, t) / \partial t=-\nabla J(r, t)=D \nabla^{2} w(r, t), \quad \in V,
$$

where Eq. (1) is used to arrive at the right-hand side of Eq. (3), and $\nabla^{2}$ is the Laplace operator. In the presence of an omni-directional sound source within a room region or domain $(V)$ with time-dependent energy density, Eq. (3) has to take the omni-directional sound source, $q(r, t)$, into account $^{33}$

$$
\frac{\partial w(r, t)}{\partial t}-D \nabla^{2} w(r, t)=q(r, t), \quad \in V,
$$

where $\nabla^{2}$ is Laplace operator, $D$ is the diffusion coefficient.
In Eq. (4), the source term $q(r, t)$ is zero for any subdomain in which no source is present. To generate the steadystate derived sound energy decay, a switch-off signal to the source term is assigned by ${ }^{9}$

$$
q\left(r_{s}, t\right)=E_{0} \zeta(t)
$$

where

$$
\zeta(t)= \begin{cases}1, & t \leq 0 \\ 0, & t>0\end{cases}
$$

Physically, the sound source, a point source, is turned on for a long-enough period of time to establish steady-state field conditions and is then switched off at a time point referred to as $0 \mathrm{~ms}$. In the numerical implementation, it requires a timedependent solution already before $t=0$ in order to ensure the system arrives at the steady-state. ${ }^{9}$ The energy flow level is then defined as ${ }^{35}$

$$
\begin{aligned}
J_{L}(r, t)= & 10 \log _{10}\left\{\left[\frac{\partial w(r, t)}{\partial x}\right]^{2}+\left[\frac{\partial w(r, t)}{\partial y}\right]^{2}\right. \\
& \left.+\left[\frac{\partial w(r, t)}{\partial z}\right]^{2}\right\}^{1 / 2} .
\end{aligned}
$$

\section{Boundary conditions}

The effects of enclosing room surfaces can analytically be expressed by boundary equations defined on the boundary surfaces $(S)$. If the sound energy in an enclosure/domain $(V)$ cannot escape from bounded surfaces $(S)$, then the boundary condition equation becomes ${ }^{33}$

$$
J(r, t) \cdot n=-D \nabla w(r, t) \cdot n=0 \quad \text { on } V,
$$

where $n$ is the surface outgoing normal, $D$ is the "diffusion coefficient," and $w(r, t)$ is the acoustic energy density at a position $(r)$ and time $(t)$. The position $(r)$ is specifically on the interior surfaces. Equation (8) is a so-called homogeneous Neumann boundary condition. ${ }^{33}$ The boundary 
condition established to include energy exchanges on enclosing surfaces is

$$
J(r, t) \cdot n=-D \nabla w(r, t) \cdot n=A_{X} c w(r, t) \quad \text { on } S,
$$

where $A_{X}$ is an exchange coefficient or the so-called modified absorption factor, which is expressed as follows: ${ }^{34}$

$$
A_{X}=\frac{\alpha}{4(1-\alpha / 2)}
$$

where $\alpha$ is the absorption coefficient of the specific surface or boundary. The diffusion equation model with this boundary condition is accurate for both modeling rooms with low absorption, as in the case of Hagia Sophia, as well as for mixed boundary conditions associated with high absorption for specific room surfaces, as in the case of Süleymaniye Mosque.

Combining Eqs. (9) and (10) gives the resulting system boundary equation as follows:

$$
-D \frac{\partial w(r, t)}{\partial n}=\frac{c \alpha}{4(1-\alpha / 2)} w(r, t) \quad \text { on } S .
$$

Another boundary condition is the continuous boundary of the coupling aperture, applied in multi-domain solutions, which has to fulfill the following condition: ${ }^{36}$

$$
\hat{n} \cdot\left[D_{1} \nabla w\left(r_{b}, t\right)-D_{2} \nabla w\left(r_{b}, t\right)\right]=0,
$$

which represents a continuity boundary condition on interior boundaries at the aperture position $r_{b}$, where $D_{1}$ is the diffusion coefficient in the primary room and $D_{2}$ is the diffusion coefficient for the secondary room. For the two rooms with proportionate dimensions, $D_{i}=\lambda_{i} c / 3$, with $\lambda_{i}$ being the MFP of each individual rooms.

In order to obtain the time-dependent solution, Eqs. (4), (5), (11), and (12) are applied where necessary. Resulting $w(r, t)$ can be converted into sound level (SL) in decibels by

$$
S L=10 \log _{10} w(r, t) .
$$

This study employs Fick's law expressed in Eqs. (1) and (7) in sound energy flow vector and energy flow decay analysis discussed in Sec. IV.

\section{B. Numerical implementation}

\section{Meshed models}

In order to validly apply the above described diffusion equation in room acoustic scenarios, the scattering sound particle density must be high, and the reflection of energy must dominate over absorption in the space under investigation. ${ }^{30}$ Both historically significant case structures of this study have many decorative interior elements and the majority of the interior surfaces are highly reflective. The major difference between Süleymaniye Mosque and Hagia Sophia is that the former has a carpet floor finish, whereas the latter has a marble floor pavement. Another difference is that with its larger rectangular plan and balcony (gallery) level sub-
TABLE I. Volume $(V)$, surface area $(S)$, mean free path (MFP), and diffusion coefficient $(D)$ information for single and multi-domain scenarios of Süleymaniye Mosque and Hagia Sophia models.

\begin{tabular}{lcccc}
\hline \hline Süleymaniye & $V\left(\mathrm{~m}^{3}\right)$ & $S\left(\mathrm{~m}^{2}\right)$ & MFP $(\mathrm{m})$ & $D$ \\
\hline Single Domain & 73848 & 18293 & 16.2 & 1846 \\
D0 & 55525 & 10873 & 20.4 & 2336 \\
D1 & 2240 & 1300 & 6.9 & 788 \\
D2 & 2279 & 1115 & 8.2 & 934 \\
D3 & 1892 & 1129 & 6.7 & 766 \\
D4 & 3063 & 1557 & 7.9 & 900 \\
D5 & 2820 & 1289 & 8.8 & 1000 \\
Hagia Sophia & $V\left(\mathrm{~m}^{3}\right)$ & $S\left(\mathrm{~m}^{2}\right)$ & MFP $(\mathrm{m})$ & $D$ \\
\hline Single Domain & 145020 & 38579 & 15.0 & 1720 \\
D0 & 95960 & 17647 & 21.8 & 2487 \\
D1 & 2575 & 1241 & 8.3 & 949 \\
D2 & 625 & 468 & 5.3 & 611 \\
D3 & 4430 & 2158 & 8.2 & 939 \\
D4 & 6771 & 3434 & 7.9 & 902 \\
D5 & 2395 & 1728 & 5.6 & 635 \\
D6 & 4254 & 2328 & 7.3 & 836 \\
D7 & 2499 & 1190 & 8.4 & 960 \\
D8 & 782 & 584 & 5.4 & 613 \\
D9 & 3625 & 1938 & 7.5 & 855 \\
\hline \hline
\end{tabular}

volumes, Hagia Sophia's volume doubles the volume of Süleymaniye Mosque (Table I). On the other hand, the arches of Hagia Sophia, behaving as coupling apertures, are much smaller than those of Süleymaniye Mosque (Table II).

In order to implement the DEM numerically in a finite element medium, initially the acoustical models of each structure are built. The effect of coupling of different subvolumes are searched in single and multi-domain solutions. Thus, first, results are obtained for the single domain, meaning a single diffusion coefficient, Eq. (2), assigned for the whole structure. Second, specific diffusion coefficients in

TABLE II. Surface area $\left(\mathrm{m}^{2}\right)$ matrix of apertures that are coupling subdomains (D1-D9) to each other and sub-domains to main domain (D0) in Süleymaniye Mosque and Hagia Sophia models.

\begin{tabular}{lcccccccccc}
\hline \hline Süleymaniye & D0 & D1 & D2 & D3 & D4 & D5 & & & & \\
\hline D0 & - & 120 & 120 & 51 & 139 & 120 & & & \\
D1 & 120 & - & - & 93 & - & - & & & \\
D2 & 120 & - & - & 93 & - & - & & & \\
D3 & 51 & 93 & 93 & - & 84 & 93 & & & \\
D4 & 139 & - & - & 84 & - & - & & & \\
D5 & 120 & - & - & 93 & - & - & & & \\
Hagia Sophia & D0 & D1 & D2 & D3 & D4 & D5 & D6 & D7 & D8 & D9 \\
\hline D0 & - & 22 & - & 41 & $15 \& 24$ & - & $19 \& 26$ & 14 & 8 & 18 \\
D1 & 22 & - & 60 & - & 15 & - & - & - & - & - \\
D2 & - & 60 & - & 60 & - & - & - & - & - & - \\
D3 & 41 & - & 60 & - & - & - & - & - & - & - \\
D4 & $15 \& 24$ & 15 & - & - & - & 13 & - & - & - & - \\
D5 & - & - & - & - & 13 & - & - & - & - & - \\
D6 & $19 \& 26$ & - & - & - & - & - & - & 12 & - & - \\
D7 & 14 & - & - & - & - & - & 12 & - & 60 & - \\
D8 & 8 & - & - & - & - & - & - & 60 & - & 60 \\
D9 & 18 & - & - & - & - & - & - & - & 60 & - \\
\hline \hline
\end{tabular}




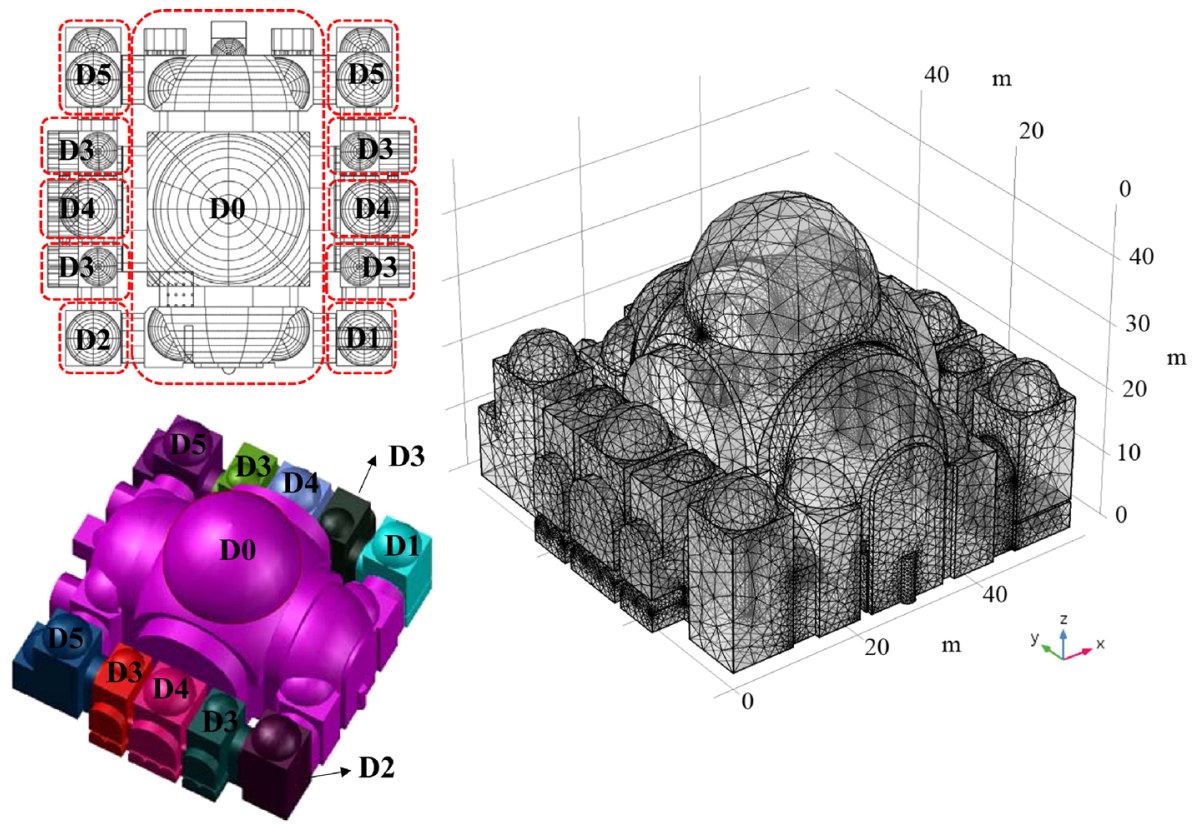

FIG. 2. (Color online) Süleymaniye Mosque mesh model (on the right); total of 164468 linear Lagrange-type mesh elements; mesh size; min: $0.62 \mathrm{~m}$, max: $4.96 \mathrm{~m}$; plan view (on the top left) and axonometric (on the bottom left) of 3D model with individual domain numbers.

relation to their MFPs are defined for sub-volumes, termed sub-domains hereon. In the process of defining sub-domains, architectural details are taken into account. Coupling apertures of both structures are the arches that connect subspaces to each other sheltered mostly with domes or vaults of different sizes.

Volumes underneath smaller domes on side aisles of Süleymaniye Mosque are considered as distinct domains, which are separated by arches from each other as well as from the main space (main prayer hall). In Hagia Sophia, the narthex, aisles, galleries (at balcony level) sheltered with various style of vaults are connected to the main space (nave) with arches in different sizes, which are all treated as individual domains. Figure 2 presents a mesh model of Süleymaniye Mosque, and Fig. 3 illustrates the mesh model of Hagia Sophia. Individual domains of three-dimensional (3D) models are highlighted on plan and axon views (Fig. 2 and Fig. 3).

The geometric model of Süleymaniye Mosque has 164468 linear Lagrange-type mesh elements (Fig. 2), while
Hagia Sophia model has 691865 linear Lagrange-type mesh elements (Fig. 3). Minimum mesh size is $0.62 \mathrm{~m}$ for Süleymaniye mosque and $0.39 \mathrm{~m}$ for Hagia Sophia. Maximum mesh size is $4.96 \mathrm{~m}$ for Süleymaniye Mosque and $5.31 \mathrm{~m}$ for Hagia Sophia. As long as the maximum mesh size is smaller than the mean free path of the room, the DEM is applicable. In this case, the range of mesh sizes are in between 1/4 and 1/11 of MFP for Süleymaniye Mosque and between 1/4 and 1/14 of MFP for Hagia Sophia. Thus, maximum mesh sizes of both models satisfy the MFP criteria for the DEM.

On the other hand, the minimum size depends on the geometrical attributes of the spaces under consideration. For instance, the transitions between domes and adjacent arches in both models generate smaller surfaces requiring smaller mesh sizes at those locations. A pure cubical form could be meshed with larger-sized thus fewer numbers of elements. The timedependent simulation takes approximately $13 \mathrm{~min}$ on a computer with Intel(R) Xeon(R) E5-1650 CPU, @ 3.60 GHz

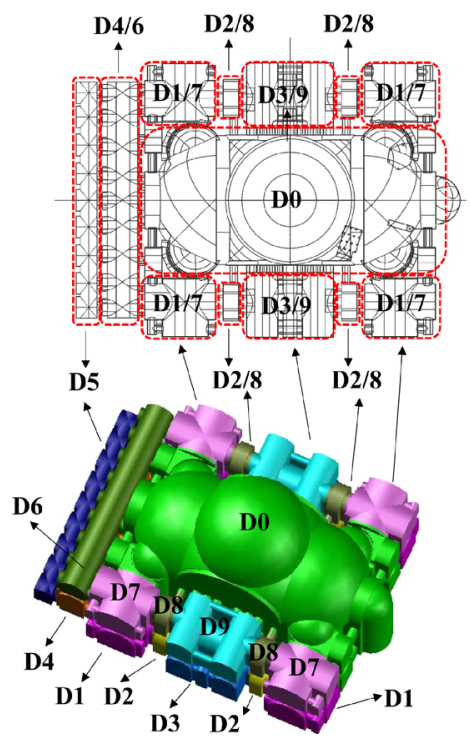

J. Acoust. Soc. Am. 145 (4), April 2019

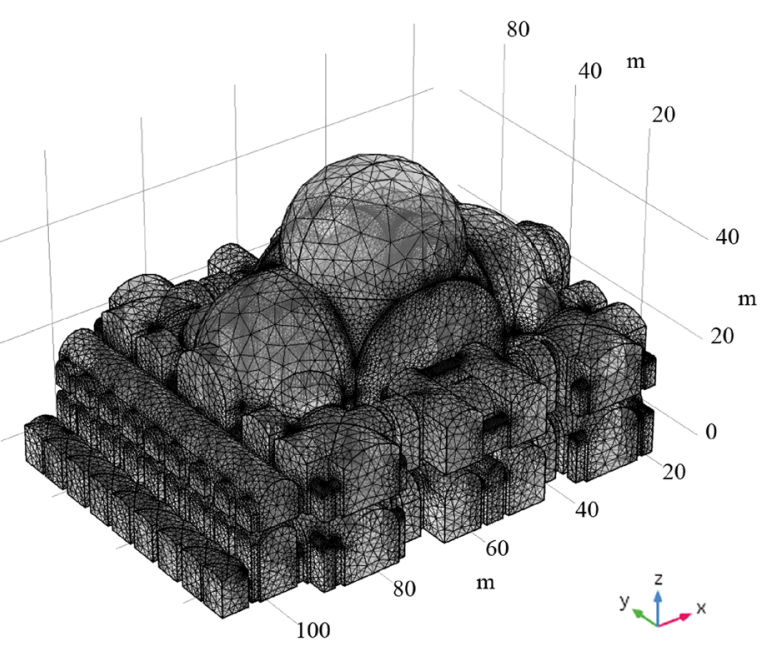

FIG. 3. (Color online) Hagia Sophia mesh model (on the right); total of 691865 linear Lagrange-type mesh elements; mesh size; min: $0.39 \mathrm{~m}$, max: $5.31 \mathrm{~m}$; plan view (on the top left) and axonometric (on the bottom left) of 3D model with individual domain numbers. 
TABLE III. The comparison of T(30) results obtained at field test, from ray tracing, from DEM for single domain (DEM_s), and for multi-domain (DEM_m), for $S_{1} R_{3}$ test position of Hagia Sophia for $1 \mathrm{kHz}$ and $250 \mathrm{~Hz}$.

\begin{tabular}{lcc}
\hline \hline $\mathrm{T}(30)$ & $1 \mathrm{kHz}$ & $250 \mathrm{~Hz}$ \\
\hline Field test & 8.18 & 10.02 \\
Ray tracing & 7.14 & 9.05 \\
DEM_s & 7.75 & 9.29 \\
DEM_m & 8.30 & 9.55 \\
\hline \hline
\end{tabular}

processor for Süleymaniye Mosque and $1 \mathrm{~h} / 4 \mathrm{~min}$ for Hagia Sophia models. Table I lists the volume and the total surface area of individual domains. Accordingly, the MFPs and diffusion coefficients $(D)$ are calculated for different domains of case structures. Table II lists aperture surface areas that are coupling different sub-domains (D1-D9) to each other and sub-domains to main domain (D0).

\section{Model tuning}

Meshed models are fine-tuned with field test results taking the reverberation time into account. For the sake of briefness of this paper, two representative octave bands are selected for the analysis; $250 \mathrm{~Hz}$, from low-range, and $1 \mathrm{kHz}$, from mid-range. In Süleymaniye model average sound absorption coefficients of 0.095 for $1 \mathrm{kHz}$ and of 0.038 for $250 \mathrm{~Hz}$ are assigned for upper shelter, stone, and plaster surfaces. The absorption coefficient of the carpet is 0.230 for $1 \mathrm{kHz}$ and 0.140 for $250 \mathrm{~Hz} .^{12}$ The modified boundary condition suits situations where a small portion of surfaces is moderately absorptive or one boundary absorbs a portion of the sound energy. ${ }^{34}$ With this modified boundary condition, the DEM is applicable $\mathrm{e}^{36,37}$ provided that the sound absorption coefficient for the small surface involved is less than 0.30 , as in the case of Süleymaniye Mosque for $1 \mathrm{kHz}$ and below.

In tuning of the Hagia Sophia model, several field tested locations are selected with single slope decay characteristics. Field-tested Schroeder decays with single slope are compared to sound energy level decay of the DEM, for both single and multi-domain solutions. Reverberation times of Hagia Sophia, for the single domain scenario, are also checked in a ray-tracing model. Absorption coefficients of materials are tuned specifically for multi-domain DEM versus field results. Accordingly, average sound absorption coefficients of 0.094 for $1 \mathrm{kHz}$ and of 0.080 for $250 \mathrm{~Hz}$ are assigned for the upper shelter, stone, and plaster surfaces.
On the other hand, for marble floor surfaces, 0.010 is attained for both $1 \mathrm{kHz}$ and $250 \mathrm{~Hz}$.

For a specific source-receiver configuration $\mathrm{S}_{1} \mathrm{R}_{3}$ (Fig. 1), a position with a single sound energy decay rate, $\mathrm{T}(30)$ is compared for the DEM-single domain, the DEM-multi domain and the ray-tracing results for $1 \mathrm{kHz}$ and $250 \mathrm{~Hz}$ (Table III and Fig. 4). The same sound absorption coefficients are assigned to the surfaces of the same acoustical model in ray tracing and DEM simulations. The ray tracing simulations estimate relatively lower decay times in comparison to DEM solutions for matching conditions. A similar outcome, lower sound attenuation in DEM solution in comparison to raytracing, is also previously pointed out in the study of Billon et $a l .{ }^{8}$ for some specific conditions. On the other hand, single domain DEM solution decay times are found to be slightly lower than multi-domain results. The size and complexity of Hagia Sophia is rather high. Such variations between different estimation methods in a modest-sized structure may be much lower.

\section{RESULTS AND DISCUSSION}

An investigation of multi-slope decay formation necessitates the interpretation of architectural inputs in relation to room acoustics coupling. The effects of architectural variables including coupling apertures, volume, and geometry of domains can better be analyzed through energy flow distribution in a DEM solution. Energy flow decays figuring energy flow dips are also correlated with the turning points in a non-exponential energy decay. This section discusses the results of numerical implementation by the analysis of energy flow decays, energy flow vectors, and coupling factors in relation to the mechanism of multi-rate sound energy decays.

\section{A. Energy flow decay analysis}

\section{Süleymaniye Mosque flow decays}

For Süleymaniye Mosque, a previous study ${ }^{11}$ discusses the causes of multi-slope formation by its DEM simulation with a single diffusion coefficient, on a single domain. This paper investigates the effects of single and multi-domain approaches on the results of the analysis. The dips or convex form of the energy flow decay curve prefigure the multi-rate decay formation, either the coupling is weak or strong.
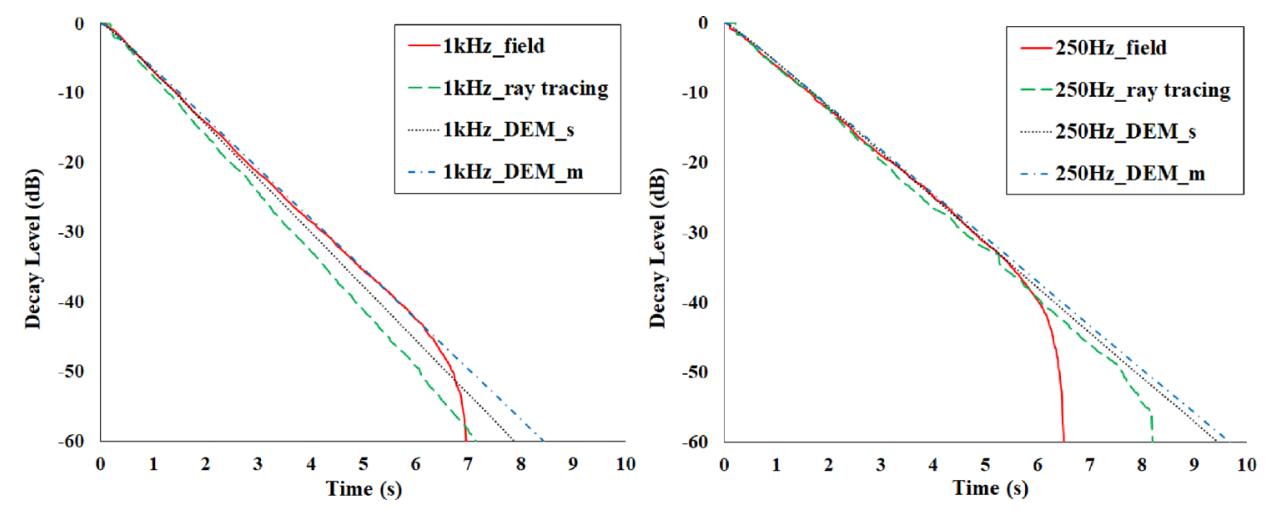

FIG. 4. (Color online) Sound energy decay comparisons of data obtained at field test, from ray tracing, from DEM for single domain (DEM_s) and for multi-domain (DEM_m); for $\mathrm{S}_{1} \mathrm{R}_{3}$ test position of Hagia Sophia for $1 \mathrm{kHz}$ and $250 \mathrm{~Hz}$. 

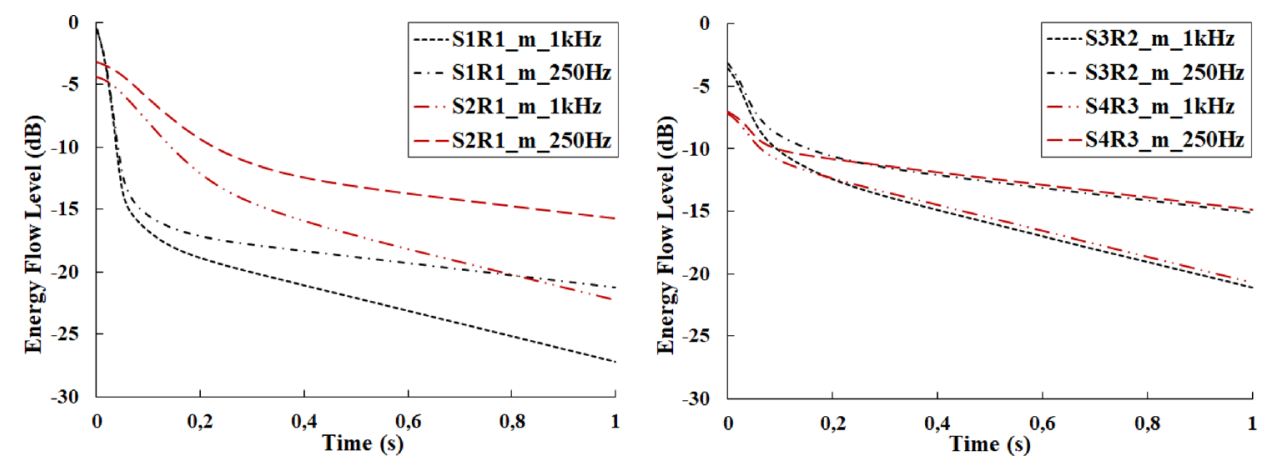

FIG. 5. (Color online) Comparison of energy flow decay results for $250 \mathrm{~Hz}$ versus $1 \mathrm{kHz}$; Süleymaniye Mosque multi-domain DEM solutions computed at $S_{1} R_{1}, S_{2} R_{1}, S_{3} R_{2}$, and $S_{4} R_{3}$.

The results are grouped and presented in two graphic forms for clarity. Initially, Fig. 5 highlights a group of results with a comparison of $250 \mathrm{~Hz}$ versus $1000 \mathrm{kHz}$ for different source-receiver configurations including $S_{1} R_{1}$, $\mathrm{S}_{2} \mathrm{R}_{1}, \mathrm{~S}_{3} \mathrm{R}_{2}$, and $\mathrm{S}_{4} \mathrm{R}_{3}$. Later, Fig. 6 compares single versus multi domain energy flow decay results computed at $S_{2} R_{8}$, $S_{4} R_{5}, S_{1} R_{4}$, and $S_{3} R_{7}$ for $250 \mathrm{~Hz}$ and $1 \mathrm{kHz}$. For the initial part of the decays, DEM solutions for $1 \mathrm{kHz}$ and $250 \mathrm{~Hz}$ do not show a significant discrepancy rather than $1-2 \mathrm{~dB}$ shifts over decay level axis (Fig. 5). The later part of the decay correlates with the difference between later reverberant decays, which is higher in $250 \mathrm{~Hz}$ as expected, indicating a shallower decay pattern. According to Fig. 6, there are some variations in energy flow decays between single and multi-domain solutions depending upon the tested sourcereceiver positions as can be observed for $S_{4} R_{5}, S_{1} R_{4}$, and $S_{3} R_{7}$. For configuration of $S_{2} R_{8}$, there is even a higher degree of variance in the energy flow decay patterns of single versus multi-domain solution, especially at the initial flow decay part (up to $200 \mathrm{~ms}$ ). This is the only position out of field tested configurations where there are three different domains on the way from the source to the receiver in its multi-domain solution. The rest of the configuration paths follow either one or two domains.

The energy flow decay patterns are correlated with the energy flow returns from different parts, domains, of the space under consideration. ${ }^{9}$ The flow decay is instructive when the mechanism of energy overlaps due to architectural features that are examined. The convex forms of energy flow decays of Süleymaniye Mosque indicate an energy return, either a full or partial return. The correlation between flow decay patterns and flow returns are discussed in more detail for Hagia Sophia in Sec. IV A2.

\section{Hagia Sophia flow decays}

For the case of Hagia Sophia, initially the single versus multi-domain DEM solutions are compared (Fig. 7) for both $1 \mathrm{kHz}$ and $250 \mathrm{~Hz}$, for source-receiver configurations where multi-slope decay is observed in field tests. ${ }^{20}$ Figure 7 presents typical cases of single versus multi domain energy flow decay analysis. In this case, most of the data indicates a variance in the pattern of energy flow decay. In comparison to single domain results, multi-domain flow decays point out either a convex form-faster or steep initial decay followed by a slower or shallower later decay-as in the case of $S_{1} R_{4}$ and $S_{2} R_{5}$, or a sharper dip, as in the case of $S_{1} R_{1}$ and $S_{2} R_{1}$. So, when the dips do not appear well in a single domain solution, the multi-domain solution starts to visualize such formation. Similar to the Süleymaniye Mosque results, DEM solutions of Hagia Sofia for $1 \mathrm{kHz}$ and $250 \mathrm{~Hz}$ do not show a significant discrepancy rather than a shallower later decay in $250 \mathrm{~Hz}$, indicating a higher late reverberance, as shown in Fig. 8 for some typical positions, including $S_{1} R_{2}$ and $S_{3} R_{1}$.

In Table IV, the amount of decay slopes observed in field test results are presented for identical source-receiver configurations to DEM. Decay parameter estimations of field tested data are performed by Bayesian model-based decay analysis ${ }^{21}$ as presented in a previous study. ${ }^{20}$ Comparative evaluation of Fig. 7 and Table IV on $S_{1} R_{1}$ and $S_{2} R_{1}$ results indicates a significant dip in their energy flow decays, corresponding to a double-slope energy decay in line with their field tests. $S_{1} R_{4}, S_{2} R_{5}$, and $S_{3} R_{1}$ positions show prominent convex energy flow decay, consistent with the double slope decay of their field data result (Figs. 7 and 8). On the other hand, at configurations of $S_{1} R_{3}, S_{2} R_{2}$, and $S_{2} R_{3}$ the convex form of energy flow decay starts to disappear with no
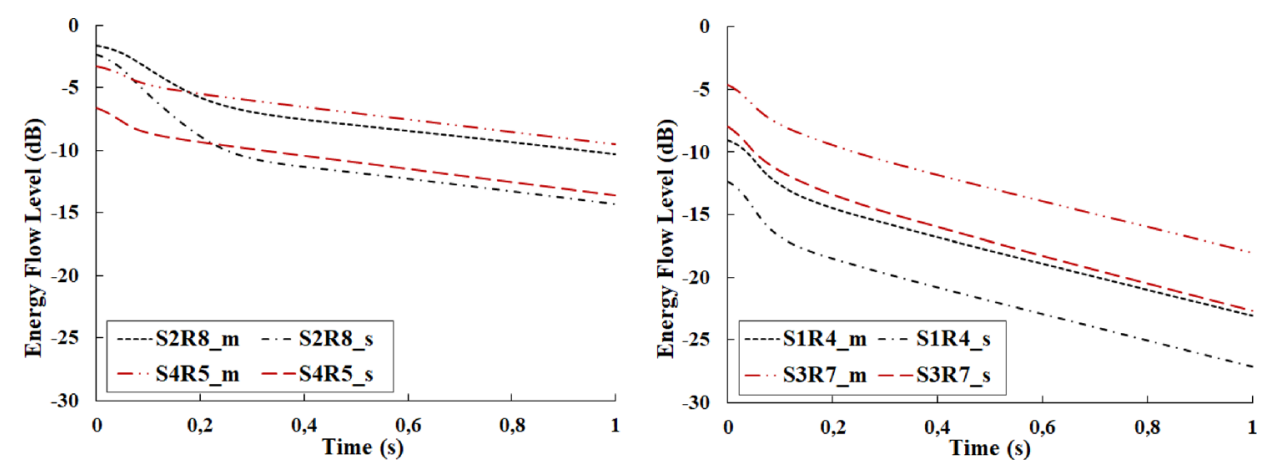

FIG. 6. (Color online) Süleymaniye Mosque DEM solutions for single ("s") versus multi-domain ("m") energy flow decay results; for $250 \mathrm{~Hz}$ (on the left) and for $1 \mathrm{kHz}$ (on the right), computed at $\mathrm{S}_{2} \mathrm{R}_{8}, \mathrm{~S}_{4} \mathrm{R}_{5}, \mathrm{~S}_{1} \mathrm{R}_{4}$, and $\mathrm{S}_{3} \mathrm{R}_{7}$. 

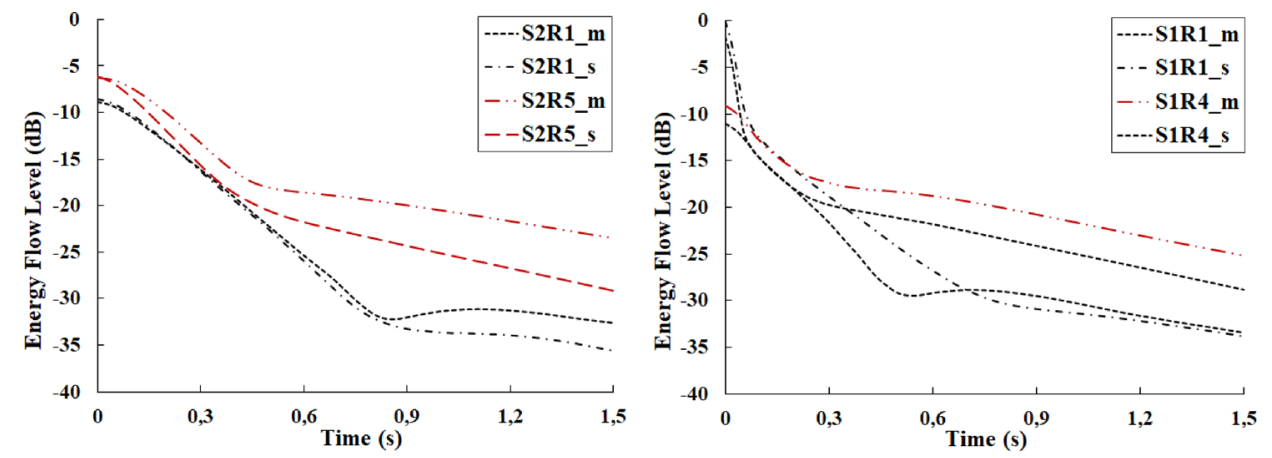

FIG. 7. (Color online) Hagia Sophia DEM solutions for single ("s") versus multi-domain (" $m$ ") energy flow decay results; for $250 \mathrm{~Hz}$ (on the left) and for $1 \mathrm{kHz}$ (on the right), computed at $\mathrm{S}_{2} \mathrm{R}_{1}$, $\mathrm{S}_{2} \mathrm{R}_{5}, \mathrm{~S}_{1} \mathrm{R}_{1}$, and $\mathrm{S}_{1} \mathrm{R}_{4}$.

apparent dips, which are consistent with the single slope energy decay findings of their field tested data (Fig. 9 and Table IV).

At few measurement positions, the field data indicates multi-slope decay, while in the DEM solution, the results emphasize a comparatively linear decay as in the case of $\mathrm{S}_{1} \mathrm{R}_{5}$ and $\mathrm{S}_{2} \mathrm{R}_{6}$ (Fig. 9 and Table IV). In particular, the triple slope decay in field tested $S_{2} R_{6}$, may be indicating a flutter echo formation in the real condition. Such phenomena cannot be distinguished or observed in a DEM simulation, as it does not rely on the wave equation. The results of DEM can be considered more generic and give an overview of effects due to absorption and volume-area ratios corresponding to the changes in the mean free path. This is one of the disadvantages of DEM.

To sum up, energy flow decay dips are very evident in multi-domain solution, particularly for relatively strong coupling conditions. Results reveal that, multi-domain DEM solution of Hagia Sophia is more indicative for multi-rate decay analysis in comparison to its single domain solution. On the other hand, due to the nature of the diffusion equation, changing absorption coefficients by absorption factor, boundary absorption, or impedance term does not significantly affect the characteristic of decay for $1 \mathrm{kHz}$ and $250 \mathrm{~Hz}$ in early time instants. The variations in between octave bands are very obvious in overall single decay rates, as in T30, due to the changes in total effective surface absorption in relation to reverberation.

In multi-slope decay formation, the most prominent results are observed at source-receiver configurations of

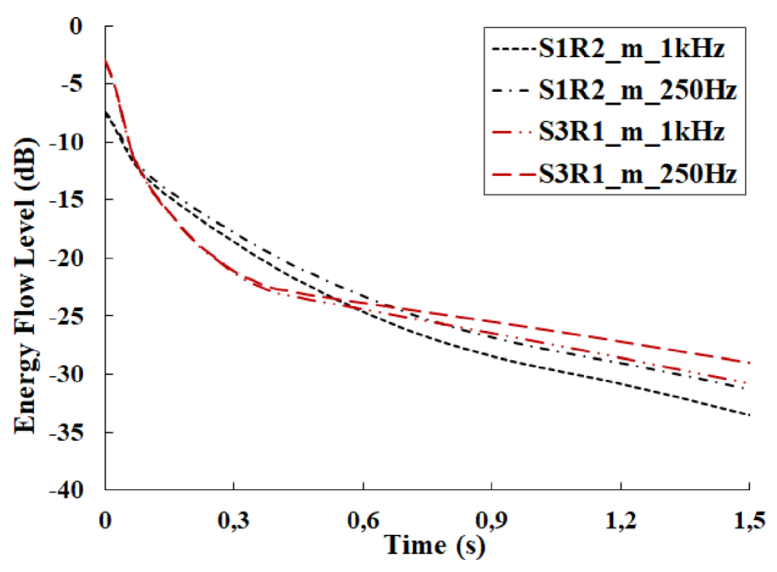

FIG. 8. (Color online) Hagia Sophia multi-domain energy flow decay results; for $250 \mathrm{~Hz}$ versus $1 \mathrm{kHz}$, computed at $S_{1} R_{2}$ and $S_{3} R_{1}$.
$\mathrm{S}_{1} \mathrm{R}_{1}$ and $\mathrm{S}_{2} \mathrm{R}_{1}$ for $1 \mathrm{kHz}$ with sharp or apparent dips on energy flow decays out of overall analyzed DEM data of Hagia Sofia model. These specific positions are compared for their energy flow decay dip times to the turning point time of the field data (Table V). The correlation of turning point time and energy flow decay dip time is previously discussed by Xiang et al. ${ }^{9}$ Accordingly, the time when the energy flow reverses its direction is correlated with the time when the dip appears on the energy flow decay curve. The reversal of energy flow direction is due to the energy feedback. When feedback dominates the primary energy decay, flow directions reverse. The dip in steady-state derived sound-energy flow decay correlates with the "turning point" in the Schroeder decay functions. A typical Schroeder decay curve derived from the room impulse response at $S_{1} R_{1}$ is given in Fig. 10, including two decomposed decay slopes and turning point estimated by the Bayesian analysis. ${ }^{21}$

In Table $\mathrm{V}$, it can be observed that the turning point times for the same source-receiver configuration from field data are two to three times later than those estimated for multi-domain DEM solutions of Hagia Sophia. On the other hand, there is still a steady difference in between analyzed positions where DEM dip times are consistently earlier than those corresponding field results. This outcome is mainly due to the fact that the DEM solution is only valid after 2 or 3 mean free times after the direct sound. ${ }^{36}$ The architectural or geometrical grounds in relation to such energy flow-decay dip phenomena are further investigated in the following section by energy flow-vector analysis.

\section{B. Energy flow vector analysis}

Energy flow decays and energy flow vectors, estimated by Eqs. (1) and (7) are correlated and can be exploited to support and further discuss the occurrence of energy dips on sound energy flow decays. This section analyzes flow vectors gathered in multi-domain DEM solution of Hagia Sophia for sample source-receiver configurations.

Sound-energy flow vectors (arrow surface plots) are presented over plan and two section planes (Figs. 11-13).

TABLE IV. Hagia Sophia field test results of tested source (S1-S3) and receiver positions (R1-R6) for $1 \mathrm{kHz}$; number of decay slopes analyzed by Bayesian decay parameter estimation.

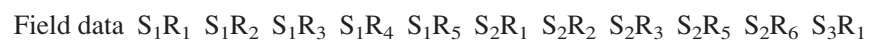

\begin{tabular}{llllllllllll}
\hline \# Slopes & 2 & 1 & 1 & 2 & 2 & 2 & 1 & 1 & 2 & 3 & 2
\end{tabular}




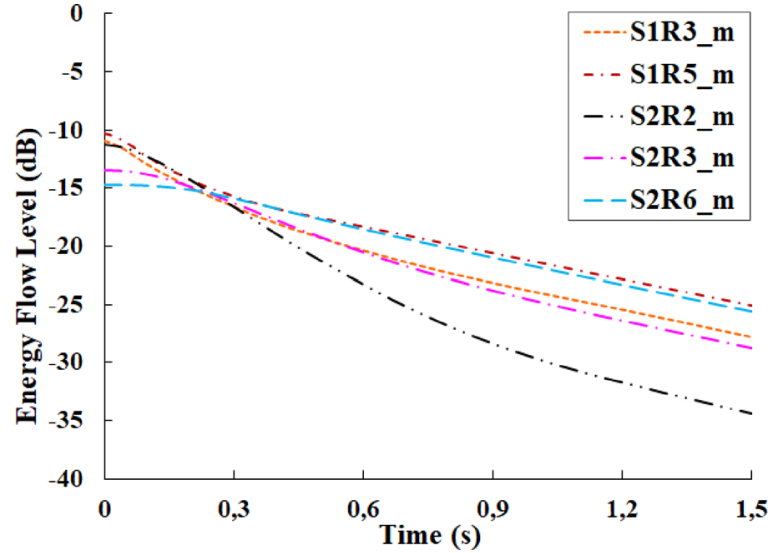

FIG. 9. (Color online) Hagia Sophia multi-domain energy flow decay results; for $1 \mathrm{kHz}$ computed at $S_{1} R_{3}, S_{1} R_{5}, S_{2} R_{2}, S_{2} R_{3}$, and $S_{2} R_{6}$.

Figure 14 summarizes close-up plan views of single point vector plots for the same locations for two time instants; first for an initial time after the sound source is stopped, then for a later time after the energy return is complete, or after the dip time. Among analyzed configurations $S_{1} R_{1}$ is a position where double-slope sound energy decay is observed in its field tests (Table IV) as well as in its DEM solutions (Fig. 7). According to multi-domain DEM result the dip time on energy flow decay is around $570 \mathrm{~ms}$ (Fig. 7). As shown in Figs. 11 and 14, in between 50 and $750 \mathrm{~ms}, S_{1} R_{1}$ plots indicate nearly an opposite flow direction or return on plan axis ( $x-y$ plane). On longitudinal ( $x-z$ plane) and transverse section $(y-z$ plane) plots, the flow vector is fully reversed. Section plots highlight that the energy feedback is dominantly from the main dome, rather than side aisles, towards $\mathrm{R}_{1}$ on ground floor (Fig. 11).

For $\mathrm{S}_{2} \mathrm{R}_{1}$, energy flow dip is even more apparent, and the dip time is around $750 \mathrm{~ms}$ for $1 \mathrm{kHz}$ (Fig. 7). In all plan and section views of energy flow plots (Fig. 12), vector reversal or full return can be clearly observed for $S_{2} R_{1}$. In Fig. 14, close-up plan view of point vector shows a $180^{\circ}$ reversal on the $x-y$ plane. Again, the energy flow is from the main dome-sheltering nave-towards $\mathrm{R}_{1}$ located $1.2 \mathrm{~m}$ above the floor on the nave. The energy flow returns are the major reason of the dips over sound energy flow decays. They are also the key indicators of double slope sound energy decays that are observed in field tested data for the same source-receiver configurations (Table IV).

A single-decay slope position from field tests (Table IV), $S_{1} R_{3}$, as previously discussed in Sec. III B 2 (Fig. 4 and Table III) is also searched for its flow vector returns in Figs. 11 and 14. No directional change can be observed either on plan ( $x-y$ axis), longitudinal ( $x-z$ axis), or transverse sections

TABLE V. Energy flow dip time comparison of multi-domain DEM solution to the field-tested turning-point times of Hagia Sophia; for $S_{1} R_{1}$ and $\mathrm{S}_{2} \mathrm{R}_{1}, 1 \mathrm{kHz}$.

\begin{tabular}{lcc}
\hline \hline Time $(\mathrm{ms})$ & Turning Point & Dip DEM_m \\
\hline $\mathrm{S}_{1} \mathrm{R}_{1}$ & 1257 & 570 \\
$\mathrm{~S}_{2} \mathrm{R}_{1}$ & 2201 & 750 \\
\hline \hline
\end{tabular}

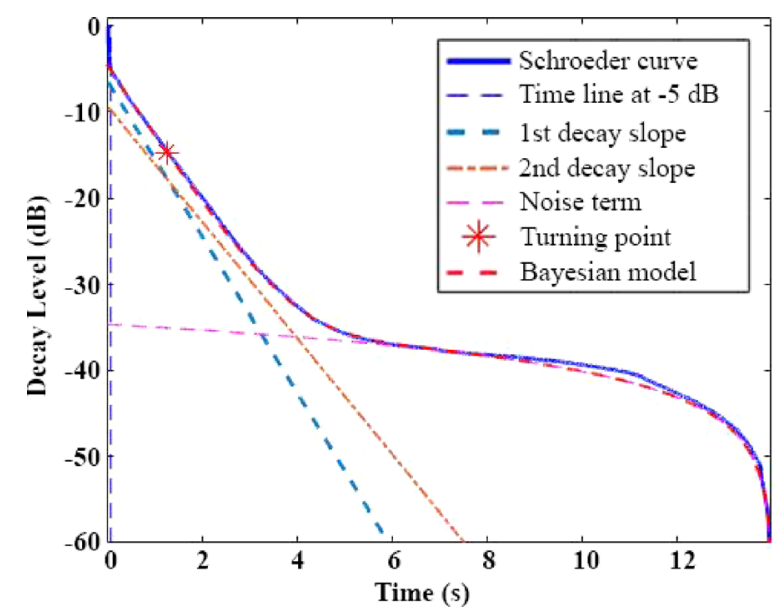

FIG. 10. (Color online) Schroeder curve and the model curve derived from impulse responses collected in Hagia Sophia at $S_{1} R_{1}$, filtered for $1 \mathrm{kHz}$; two decomposed decay slope lines and one turning point.

( $y-z$ axis) for this specific spot. For this same spot also, there is no dip occurrence over energy flow decay (Fig. 9). Field test results by Bayesian parametric estimation ${ }^{21,22}$ also indicates a single slope-exponential—sound energy decay for this source-receiver configuration. ${ }^{20}$

Finally, $\mathrm{S}_{2} \mathrm{R}_{5}$ is analyzed for energy dips versus flow vectors. At this spot, there is no obvious dip, but instead the energy flow decay illustrates only a convex form (Fig. 7). The flow vectors, as shown in Fig. 13, indicates almost a $90^{\circ}$ shift on plan view ( $x-y$ plane) and on longitudinal section $(x-z$ plane), with no change on transverse section $(x-z$ plane). Half return of flow vectors at configuration $S_{2} R_{5}$ (Fig. 14) still results in a slight curvature on energy flow decay without a noticeable dip (Fig. 7), thus indicating that the strength of energy overlap is weak; in other words, the coupling in between two sub-domains is strong.

In this section, the DEM multi-domain solution of Hagia Sophia is presented in detail to confirm and comprehend the non-exponential energy decay patterns observed in field tests. As discussed previously, especially for locations with visible energy flow dips in its multi-domain solution, as of $S_{1} R_{1}$ and $\mathrm{S}_{2} \mathrm{R}_{1}$, single domain solutions do not indicate a dip but only a convex energy decay curve (Fig. 7). Thus, it is significant that for a multi-volume structure with specific aperture to absorption area ratios, the multi-domain DEM solution should be utilized. In such cases diffusion coefficients should be attained to individual domains, rather than a single diffusion coefficient designated to the whole volume in the DEM. The aperture to absorption area ratios in relation to room acoustics coupling are further discussed in Sec. IV C.

\section{Coupling factor discussion}

Previous sections argue energy flow dips together with spatial energy flow vectors in relation to single-versus multislope sound energy decay formation. This section further elaborates the significance of multi-domain DEM simulations in multi-volume structures where multi-slope energy decays can be observed. Diffusion coefficient assignment is one key factor that describes the morphology of different 


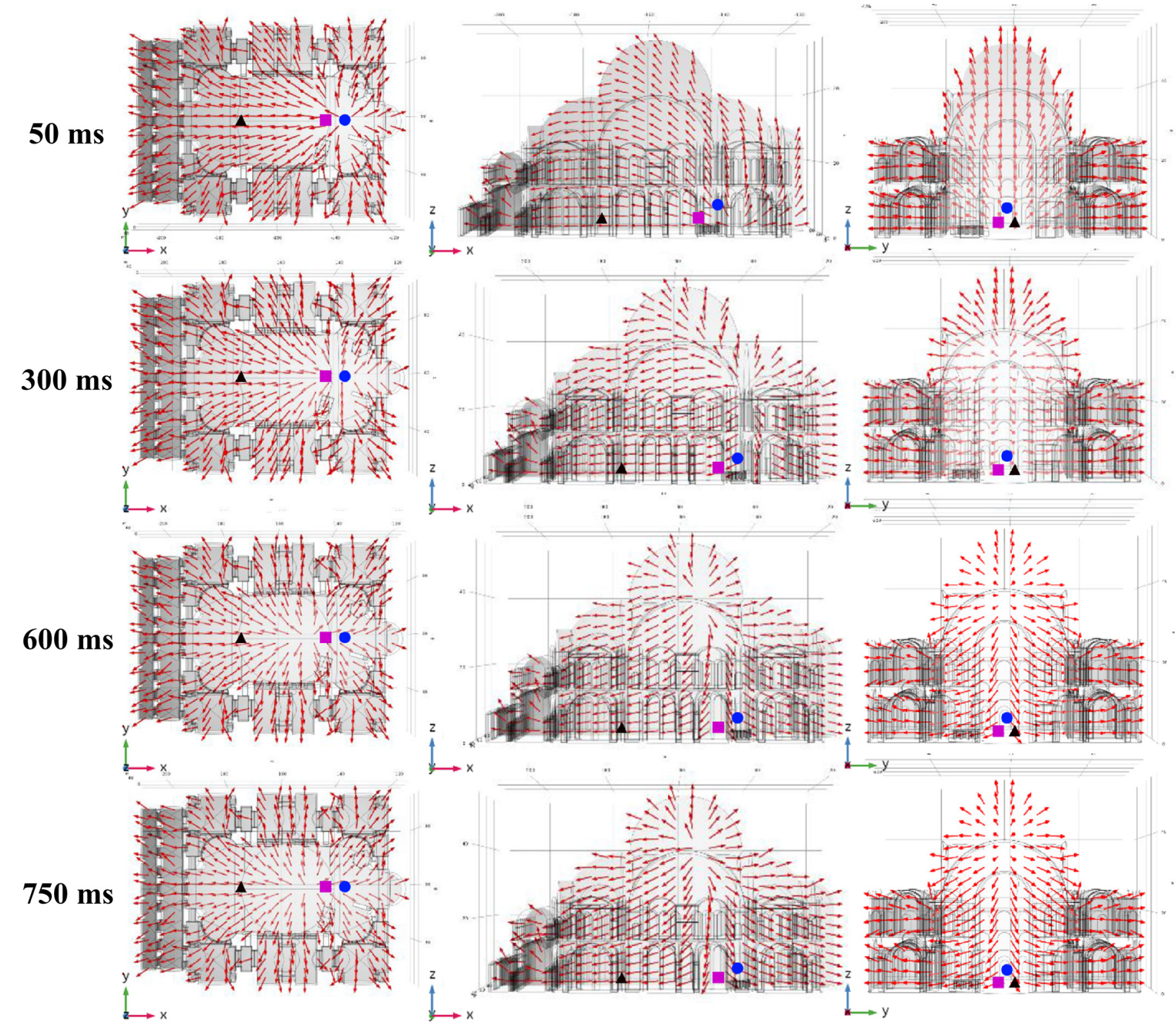

FIG. 11. (Color online) Hagia Sophia multi-domain DEM solution mapping of sound-energy flow vectors for $1 \mathrm{kHz}$ for time instants: 50, 300, 600, and $750 \mathrm{~ms}$; source-receiver locations indicated by $\mathrm{S}_{1}$ (blue circle), $\mathrm{R}_{1}$ (magenta square), $\mathrm{R}_{3}$ (black triangle); plan views, longitudinal ( $x-z$ axis) and transverse sections ( $y-z$ axis).

volumes, which are either strongly or weakly coupled to each other. In an earlier study, Billon et al. ${ }^{8}$ applied mean coupling factor $(k)$ in their comparisons of diffusion model, statistical theory, and ray tracing for acoustically coupled spaces. Mean coupling factor is defined as follows:

$$
\kappa=\sqrt{\frac{S_{c}^{2}}{\left(S_{c}+A_{R}\right)\left(S_{c}+A_{S}\right)}},
$$

where $S_{c}$ is the coupling area, $A_{R}$ is the equivalent absorption area of the receiving room, and $A_{S}$ is the absorption area of the source room. According to that, $k \approx 1$ denotes a strong coupling, while $k \approx 0$ indicates a weak coupling. ${ }^{8}$ A strong coupling means that the aperture sizes are big enough, so the two volumes should not be considered as separate domains, but instead should be considered as a single volume. Conversely, a weak coupling indicates that the apertures are small enough to consider the two volumes as part of a multidomain system.

A weak coupling necessitates the assignment of individual diffusion coefficients to each volume as in the case of Süleymaniye Mosque and Hagia Sophia. Table VI lists $k$ values obtained by Eq. (14) for specific source-receiver configurations tested in case structures. As can be observed in Table VI, considering sub-volume to main volume coupling (Tables I and II), the coupling factors are smaller than 0.30 for Süleymaniye Mosque and much smaller than 0.10 for Hagia Sophia. Although the limits of weak to strong coupling are not well defined, ${ }^{8}$ in a strong coupling indication by mean coupling factor of 1 , the values lower than 0.30 can securely be assumed to be a weak coupling. Thus, the individual volumes should be treated as individual domains with specific diffusion coefficients in DEM simulation of both cases. 


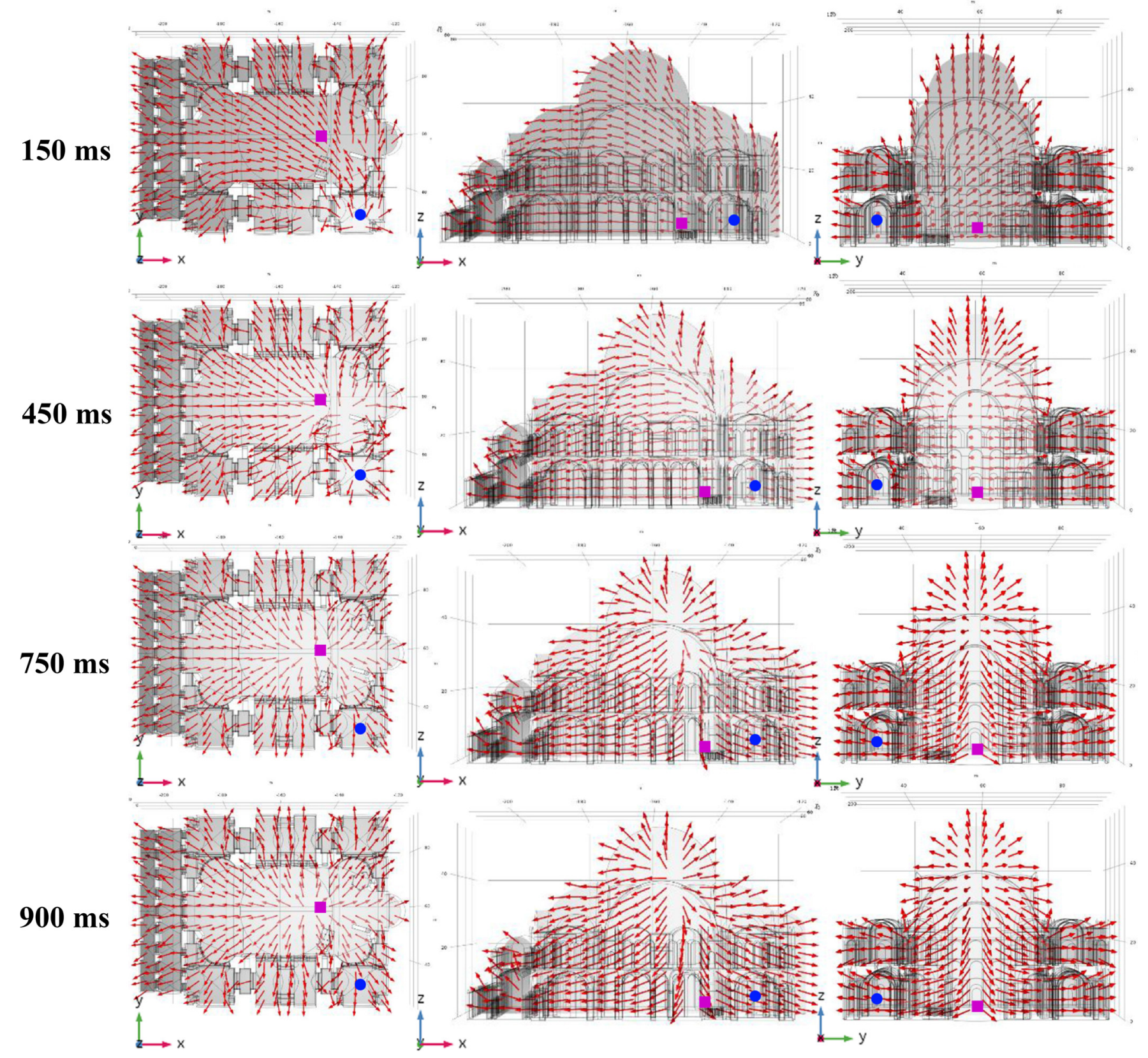

FIG. 12. (Color online) Hagia Sophia multi-domain DEM solution mapping of sound-energy flow vectors for $1 \mathrm{kHz}$ for time instants: 150 , 450 , 750 , and $900 \mathrm{~ms}$; source-receiver locations indicated by $\mathrm{S}_{2}$ (blue circle), $\mathrm{R}_{1}$ (magenta square); plan views, longitudinal ( $x-z$ axis) and transverse sections ( $y-z$ axis).

There is still a considerable difference in the mean coupling factors between Süleymaniye Mosque and Hagia Sophia. This is mainly due to the larger coupling apertures (arches) of Süleymaniye Mosque that divides main volume from smaller sub-volumes, in comparison to those of Hagia Sophia. For that reason, the energy flow dips or flow returns of Süleymaniye Mosque (Fig. 6), are not as sharp as those of Hagia Sophia (Fig. 7).

This paper has focused on exact source-receiver configurations that are tested in real-size measurements. As acoustical coupling (or multi-slope energy decay occurrence) is very much dependent on location, for both structures, there may exist other spots with different acoustical behaviors that are not particularly and practically measured in field tests. One demonstrative example is selected from each structure where receiver $\left(\mathrm{R}_{\mathrm{A}}\right)$ is located closer to its aperture in adjacency to the main volume (D0) at $5 \mathrm{~m}$ above ground (Fig. 1). When $S_{1} R_{A}$, at Süleymaniye Mosque, is compared to some other field tested locations, a greater difference between single versus multi-domain solution can be observed (Fig. 15). In $S_{1} R_{A}$ of Hagia Sophia, the dip out of multi-domain solution is more evident in comparison to its single-domain solution, as demonstrated in previous field-tested configurations (Fig. 7). The changes may even be more dramatic for some other locations where multi-slope decay is stronger. For that reason, in a systematic investigation of multi-slope sound energy decays in multi-volume structures, it is important that the domains should be defined by their specific diffusion coefficients, when the coupling by apertures can be considered as weak. Through this way, the energy flow decays can 


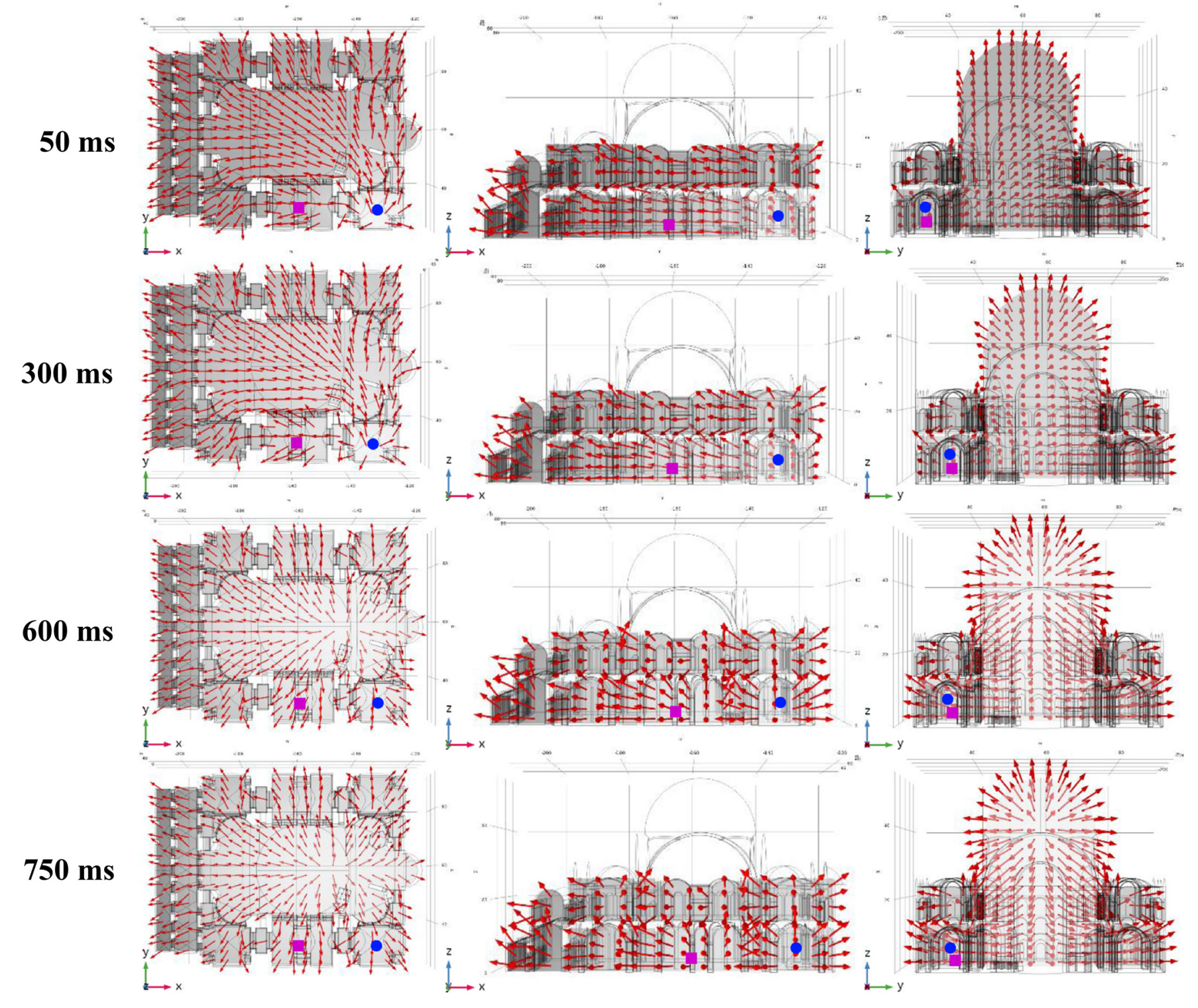

FIG. 13. (Color online) Hagia Sophia multi-domain DEM solution mapping of sound-energy flow vectors for $1 \mathrm{kHz}$ for time instants: 50, 300, 600, and $750 \mathrm{~ms}$; source-receiver locations indicated by $\mathrm{S}_{2}$ (blue circle), $\mathrm{R}_{5}$ (magenta square); plan views, longitudinal ( $x-z$ axis), and transverse sections ( $y-z$ axis).

be better utilized in detection and understanding of the phenomena.

\section{CONCLUSION}

This study investigates energy flow patterns in multidomain structures by the application of proper modeling and analysis methods over cases of Süleymaniye Mosque and Hagia Sophia, where multi-slope sound energy decays are observed in their previous field tests. ${ }^{20}$ In order to understand the mechanism of non-exponential energy decay in such multi-volume structures, the DEM in a finite-element scheme is utilized. The DEM solution has enabled energy flow decays, energy flow dips and spatial flow vectors to be visualized and analyzed in relation to room acoustics coupling.

Another concern of this study is to compare singledomain to multi-domain DEM solutions of multi-volume structures with many smaller sub-volumes coupled to each other and to a main larger volume by coupling apertures in form of arches as in the other cases of cathedrals, basilicas or mosques. In a single domain solution, the whole structure is considered as one volume with a single diffusion coefficient in the DEM. On the other hand, specific zones as of sub-volumes underneath smaller domes or vaulted aisles are considered as discrete volumes, and multi-domain solutions are applied in the DEM by associated diffusion coefficients attained to individual domains.

Single domain solution results of Süleymaniye Mosque are slightly different than its multi-domain solutions for field-tested locations. While, for some other positions, indicating a higher level of non-exponential energy decay, variations in two solutions are even greater. Consequently, the convex form of the energy flow decay becomes very apparent. On the other hand, the multi-domain DEM analysis results of Hagia Sophia are very indicative in multi-rate decay analysis in comparison to its single-domain solution. In single domain solution of Hagia Sophia, at some 

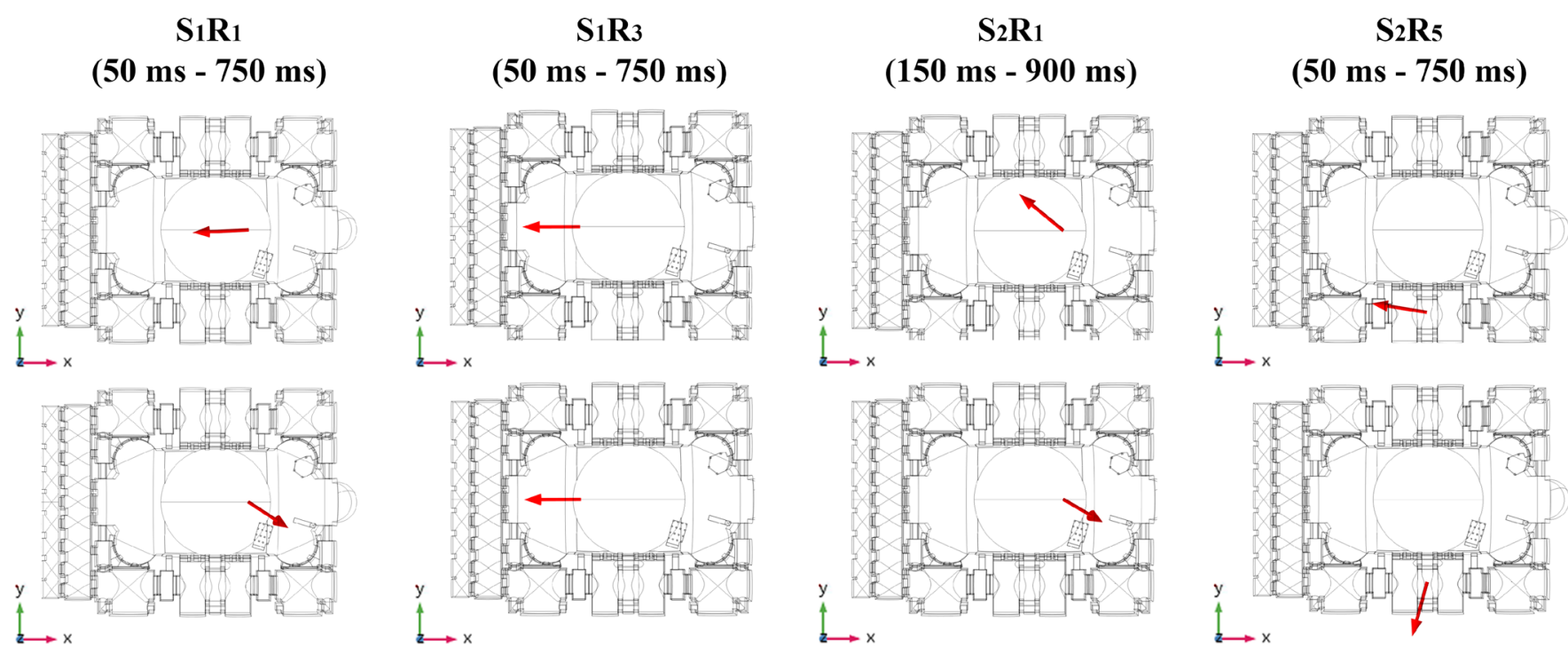

FIG. 14. (Color online) Hagia Sophia multi-domain DEM solution close-up single point flow vectors for $1 \mathrm{kHz}$ : $\mathrm{S}_{1} \mathrm{R}_{1}$ for $50 \mathrm{~ms}$ and $750 \mathrm{~ms}$; $\mathrm{S}_{1} \mathrm{R}_{3}$ for $50 \mathrm{~ms}$ and $750 \mathrm{~ms} ; \mathrm{S}_{2} \mathrm{R}_{1}$ for $150 \mathrm{~ms}$ and $900 \mathrm{~ms} ; \mathrm{S}_{2} \mathrm{R}_{5}$ for $50 \mathrm{~ms}$ and $750 \mathrm{~ms}$, initial time plots (above) and later time plots (below), plan ( $x-y$ plane) views.

particular positions the energy dips are not observed, though the same locations indicate an obvious dip over their multidomain energy flow decays, while the field tested data display a double slope over sound energy decays at these locations. In brief, there is always a difference between single versus multi-domain DEM solutions. As the coupling factor gets weaker, for instance, by smaller apertures, the difference is more obvious. Thus, for both structures, the reliable method is found to be the multi-domain solution.

Sound energy flow decays in Hagia Sophia illustrate higher levels of energy flow dips in comparison to those of Süleymaniye Mosque. The most likely reason for that difference is the aperture size versus equivalent absorption area of each structure. In order to interpret this observation, the level of coupling is further discussed by applying mean coupling factor. $^{8}$ The results indicate that in Hagia Sophia the coupling of main domain to sub-domains is weaker than those of Süleymaniye Mosque. Thus, the energy flow dips or nonexponential sound energy decays appear much stronger.

The mean coupling factors of both structures also reveal that the coupling between different volumes are still weak enough, so that they should be considered as discrete domains to be solved by multi-domain DEM approach. The

TABLE VI. Mean coupling factors $(k)$ for specific source $(\mathrm{S})$ receiver (R) configurations in relation to coupling aperture area and absorption areas of individual domains (D) coupled to each other by arches for Süleymaniye Mosque and Hagia Sophia.

\begin{tabular}{lccccc}
\hline \hline Süleymaniye $(k)$ & $\mathrm{S}_{1} \mathrm{R}_{4}$ & $\mathrm{~S}_{3} \mathrm{R}_{7}$ & $\mathrm{~S}_{4} \mathrm{R}_{5}$ & $\mathrm{~S}_{2} \mathrm{R}_{1}$ & $\mathrm{~S}_{2} \mathrm{R}_{\mathrm{A}}$ \\
\hline D0-D1 & 0.25 & - & - & - & - \\
D0-D2 & - & 0.27 & - & - & - \\
D0-D4 & - & - & 0.28 & - & - \\
D2-D0 & - & - & - & 0.27 & 0.27 \\
Hagia Sophia $(k)$ & $\mathrm{S}_{1} \mathrm{R}_{4}$ & $\mathrm{~S}_{1} \mathrm{R}_{5}$ & $\mathrm{~S}_{2} \mathrm{R}_{1}$ & $\mathrm{~S}_{2} \mathrm{R}_{2}$ & $\mathrm{~S}_{2} \mathrm{R}_{\mathrm{A}}$ \\
\hline D0-D1 & 0.05 & - & - & - & - \\
D0-D3 & - & 0.07 & - & - & - \\
D1-D0 & - & - & 0.05 & 0.05 & 0.05 \\
\hline \hline
\end{tabular}

limits of weak to strong coupling are yet to be defined. In order to specify the exact factor after which the coupled domains can be considered as a single volume, an analytic approach should be applied over either many cases, positions, or for systematically increased aperture size versus absorption area, which is a subject of a future research.

The decay patterns out of DEM solutions of both structures for different octave bands, namely, $250 \mathrm{~Hz}$ and $1 \mathrm{kHz}$, do not show a significant deviation. Owing to the nature of diffusion equation, changing absorption coefficients by absorption factor or boundary absorption or impedance term does not significantly affect the pattern of the decay, but results only as a decay rate change. This might be a disadvantage of the DEM, especially for low frequencies where wave equation may indicate some other phenomena as of room modes.

This study also discusses energy flow vectors in relation to energy flow dips, and multi-rate sound energy decays. The energy flow vectors derived from the DEM solution facilitate investigations of the energy fluxes and their flow direction

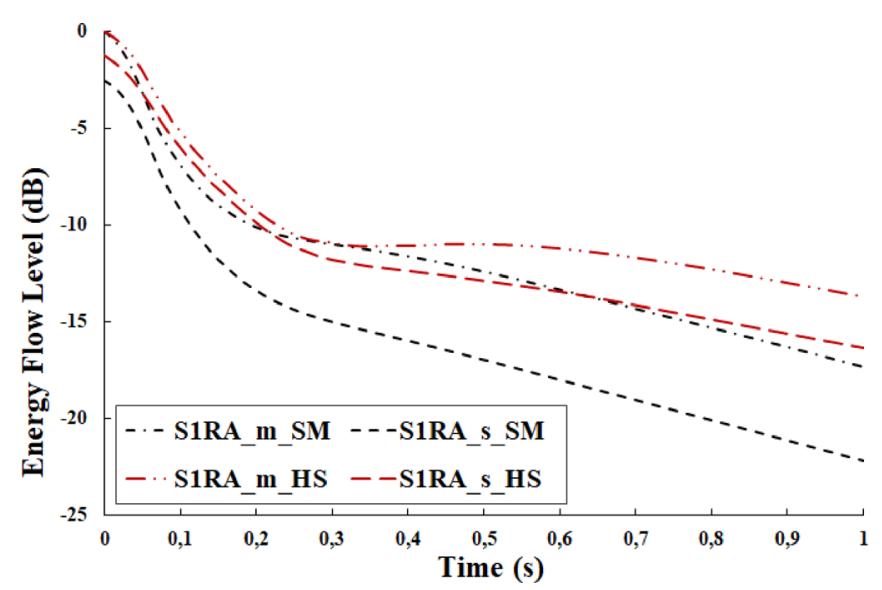

FIG. 15. (Color online) Single ("s") versus multi-domain ("m") energy flow decay results for $1 \mathrm{kHz} ; \mathrm{S}_{1} \mathrm{R}_{\mathrm{A}}$ for Süleymaniye Mosque ("SM") and Hagia Sophia ("HS") DEM solutions. 
reversal. In analyzed data, sound energy flow decays and flow dips are mostly consistent with the field tested data. For instance, at locations where a single slope is observed in field tests, energy flow dips do not appear over energy flow decays and flow vector directions are stable in a timedependent solution. Conversely, in most of the cases where double slope is observed in real data, there is either a strong dip or a convex form on the energy flow decay and there is a directional reversal on energy flow vectors, depending upon the level of coupling.

Previous work ${ }^{9}$ using DEM simulations verified that the energy flow-direction changes occur at the turning points of multi-sloped sound-energy decays estimated via Bayesian analysis. The directional characteristics of flow vectors in a time dependent solution can serve as an indicator of multislope sound energy decay. For some specific source-receiver configurations, where flow dips are evident, turning point times from field data are compared to energy flow decay dip times. Turning point times of field-tested data are consistently later than those of the DEM model. This result is expected, due to the fact that DEM solution is only valid after 2 or 3 mean free times after the direct sound. ${ }^{36}$

The energy flow vector analysis is also useful for relating the architectural or geometrical features to such energy flow decay dip occurrence or the multi-slope decay formation. In the case of Hagia Sophia, for selected sourcereceiver configurations where double-slope decays are observed in field tests, the flow vectors point out that the energy return is mostly from the main dome sheltering nave, towards the receiver positions either in the main domain or side aisles on ground floor. Thus, the accumulated sound energy in the main dome of Hagia Sophia feeds back the rest of the sub-volumes after a specific time instant around when the energy dips are observed.

Considering the computational load, the efficiency of the DEM is particularly proved for Süleymaniye Mosque, where a time dependent solution lasts around $10 \mathrm{~min}$. The complexity and the detail of Hagia Sophia, with a finemeshed model, has resulted in a longer computation time, around an hour, but still more efficient for a spatial solution when compared to a ray-tracing simulation. One disadvantage of DEM is that for each octave band, the computation should be repeated. On the other hand, in a ray-tracing simulation, the energy flow decays or flow dips cannot be observed.

In this study, the diffusion equation modeling has revealed much information on energy flow decays, energy flow dips, and flow vectors in relation to the mechanism of multi-slope decay formation. The DEM application in this study has proven to be a powerful and practical method that can accelerate room acoustics analyses, especially in complex structures with possible non-exponential decay profiles.

${ }^{1}$ G. M. Naylor, "Odeon—Another hybrid room acoustical model," Appl. Acoust. 38, 131-143 (1993).

${ }^{2}$ J. H. Rindel, "The use of computer modeling in room acoustics," J. Vibroeng. 3, 219-224 (2000).

${ }^{3}$ C. F. Eyring, "Reverberation time measurements in coupled rooms," J. Acoust. Soc. Am. 3, 181-206 (1931).
${ }^{4}$ L. Cremer and H. A. Müller, "Coupled rooms," in Principles and Applications of Room Acoustics (Elsevier, London, 1978), Vol. 1, pp. 261-292.

${ }^{5}$ E. N. Wester and B. R. Mace, "A statistical analysis of acoustical energy flow in two coupled rectangular rooms," Acta Acust. 84, 114-121 (1998).

${ }^{6}$ J. S. Anderson and M. B. Anderson, "Acoustic coupling effects in St Paul's Cathedral, London,” J. Sound Vib. 236, 209-225 (2000).

${ }^{7}$ F. Martellotta, "Identifying acoustical coupling by measurements and prediction-models for St. Peter's Basilica in Rome," J. Acoust. Soc. Am. 126, 1175-1186 (2009).

${ }^{8}$ A. Billon, V. Valeau, A. Sakout, and J. Picaut, "On the use of a diffusion model for acoustically coupled rooms," J. Acoust. Soc. Am. 120, 2043-2054 (2006).

${ }^{9}$ N. Xiang, Y. Jing, and A. C. Bockman, "Investigation of acoustically coupled enclosures using a diffusion-equation model," J. Acoust. Soc. Am. 126, 1187-1198 (2009).

${ }^{10}$ P. Luizard, J. D. Polack, and B. F. G. Katz, "Sound energy decay in coupled spaces using a parametric analytical solution of a diffusion equation," J. Acoust. Soc. Am. 135, 2765-2776 (2014).

${ }^{11} \mathrm{Z}$. Su Gul, N. Xiang, and M. Caliskan, "Investigations on sound energy decays and flows in a monumental mosque," J. Acoust. Soc. Am. 140, 344-355 (2016).

${ }^{12} \mathrm{Z}$. Su Gul, N. Xiang, and M. Caliskan, "Diffusion equation based finite element modeling of a monumental worship space," J. Comput. Acoust. 25, 1-16 (2017).

${ }^{13}$ C. M. Harris and H. Feshbach, "On the acoustics of coupled rooms," J. Acoust. Soc. Am. 22, 572-578 (1950).

${ }^{14} \mathrm{M}$. Meissner, "Computational studies of steady-state sound field and reverberant sound decay in a system of two coupled rooms," Open Phys. 5, 293-312 (2007).

${ }^{15}$ L. Nijs, G. Jansens, G. Vermeir, and M. Voorden, “Absorbing surfaces in ray-tracing programs for coupled spaces,” Appl. Acoust. 63, 611-626 (2002).

${ }^{16}$ J. E. Summers, R. R. Torres, and Y. Shimizu, "Statistical-acoustics models of energy decay in systems of coupled rooms and their relation to geometrical acoustics," J. Acoust. Soc. Am. 116, 958-969 (2004).

${ }^{17}$ J. E. Summers, R. R. Torres, Y. Shimizu, and B. L. Dalenback, "Adapting a randomized beam-axis tracing algorithm to modeling of coupled rooms via late-part ray tracing," J. Acoust. Soc. Am. 118, 1491-1502 (2005).

${ }^{18}$ A. C. Raes and G. G. Sacerdote, "Measurements of the acoustical properties of two Roman basilicas," J. Acoust. Soc. Am. 25, 954-961 (1953).

${ }^{19}$ F. Martellotta1, L Álvarez-Morales, S. Girón, and T. Zamarreño, "An investigation of multi-rate sound decay under strongly non-diffuse conditions: The Crypt of the Cathedral of Cadiz," J. Sound Vib. 421, 261-274 (2018).

${ }^{20}$ Z. Su Gul, M. Caliskan, A. Tavukcuoglu, and N. Xiang, "Assessment of acoustical indicators in multi-domed historic structures by nonexponential energy decay analysis," Acoust. Aust. 46, 181-192 (2018).

${ }^{21}$ N. Xiang, P. M. Goggans, T. Jasa, and P. Robinson, "Bayesian characterization of multiple-slope sound energy decays in coupled-volume systems," J. Acoust. Soc. Am. 129, 741-752 (2011).

${ }^{22}$ N. Xiang and P. M. Goggans, "Evaluation of decay times in coupled spaces: Bayesian parameter estimation," J. Acoust. Soc. Am. 110, 1415-1424 (2001).

${ }^{23}$ D. A. Kuban, "Symbol of Ottoman architecture: The Süleymaniye," in Ottoman Architecture (Antique Collectors' Club, Suffolk, UK, 2010), pp. 277-294.

${ }^{24}$ Süleymaniye Mosque Documents (T. R. Prime Ministry Directorate General of Foundations Archive, Ankara, Turkey, 2011).

${ }^{25}$ G. Necipoglu-Kafadar, "The Süleymaniye Complex in İstanbul: An interpretation," Muqarnas 3, 92-117 (1985).

${ }^{26}$ H. Kahler and C. Mango, Hagia Sophia (Frederick A. Praeger, New York, 1967), p. 250.

${ }^{27}$ W. E. Klenbauer, A. White, and H. Matthews, Hagia Sophia (Scala Publishers, London, 2004).

${ }^{28} \mathrm{Z}$. Su Gul, M. Caliskan, and A. Tavukcuoglu, "On the acoustics of Süleymaniye Mosque: From past to present,” Megaron 9, 201-216 (2014).

${ }^{29}$ F. Ollendorff, "Statistical room-acoustics as a problem of diffusion: A proposal,” Acustica 21, 236-245 (1969).

${ }^{30}$ J. M. Navarro, F. Jacobsen, J. Escolano, and J. J. López, “A theoretical approach to room acoustic simulations based on a radiative transfer model," Acta Acust. united Acust. 96, 1078-1089 (2010).

${ }^{31}$ J. Picaut, L. Simon, and J. D. Polack, "A mathematical model of diffuse sound field based on a diffusion equation," Acta Acust. 83, 614-621 (1997). 
${ }^{32}$ C. Visentin, N. Prodi, V. Valeau, and J. Picaut, "A numerical investigation of the Fick's law of diffusion in room acoustics," J. Acoust. Soc. Am. 132, 3180-3189 (2012).

${ }^{33} \mathrm{~V}$. Valeau, J. Picaut, and M. Hodgson, "On the use of a diffusion equation for room-acoustic prediction," J. Acoust. Soc. Am. 119, 1504-1513 (2006).

${ }^{34}$ Y. Jing and N. Xiang, "On boundary conditions for the diffusion equation in room acoustic prediction: Theory, simulations, and experiments," J. Acoust. Soc. Am. 123, 145-153 (2008).
${ }^{35}$ Y. Jing and N. Xiang, "Visualizations of sound energy across coupled rooms using a diffusion equation model," J. Acoust. Soc. Am. 124, EL360-EL365 (2008).

${ }^{36}$ N. Xiang, J. Escolano, J. M. Navarro, and Y. Jing, "Investigation on the effect of aperture sizes and receiver positions in coupled rooms," J. Acoust. Soc. Am. 133, 3975-3985 (2013).

${ }^{37}$ J. M. Navarro, J. Escolano, M. Cobos, and J. J. Lopez, "Influence of the scattering and absorption coefficients on homogeneous room simulations that use a diffusion equation model," J. Acoust. Soc. Am. 133, EL1218-EL1221 (2013). 